DOI 10.37882/2223-2982.2021.07.28

\title{
СРЕДСТВА ВЫРАЗИТЕЛЬНОСТИ В ДЕЛОВОМ АНГЛИЙСКОМ ЯЗЫКЕ (НА ПРИМЕРЕ ТЕКСТОВ ИЗ УЧЕБНОГО ПОСОБИЯ ПО ФРАНЧАЙЗИНГУ)
}

\section{MEANS OF EXPRESSIVENESS IN BUSINESS ENGLISH (BASED ON THE EXAMPLES OF THE TEXTS FROM THE TEXTBOOK ON FRANCHISING)}

N. Pokrovskaia

Summary: In this paper the object of research is the means of expressiveness in the English-language business text, and their application in teaching English-language business communication is considered as the main goal. The material of the study is the textbook "Franchising" by M.E. Ponomareva wtitten for students of the 1st year of the master's degree. It is considered by us as a vivid example of the teacher's focus on teaching future specialists in the field of international trade to easily and freely express their thoughts in English, make the students'speech more imaginative, avoid stylistic and genre uniformity of speech, apply word-making in business and professional communication.

Keywords: linguistic expressiveness, means of expressiveness, business communication, expressiveness of a business text, development of expressive business speech.

\author{
Покровская Наталья Владимировна \\ К.ю.н., Казанский (Приволжский) \\ федеральный университет \\ nataliavladimirovnapokrovskaia@gmail.com
}

Аннотация: В данной работе объектом исследования выступают средства выразительности в англоязычном деловом тексте, а в качестве основной цели рассматривается их применение в обучении англоязычной деловой коммуникации. Материалом исследования выступает учебное пособие М.Е. Пономаревой "Franchising", предназначенное для студентов 1 курса магистратуры, которое рассматривается нами как яркий пример нацеленности педагога на обучение будущих специалистов в области внешнеэкономической деятельности легко и свободно выражать свои мысли на английском языке, сделать речь обучаемых более образной, избегать стилистической и жанровой однородности речи, применять словотворчество в деловой и профессиональной коммуникации.

Ключевые слова: языковая выразительность, средства выразительности, деловая коммуникация, выразительность делового текста, развитие выразительной деловой речи. од языковой выразительностью понимается свойство текста своей словесной формой привлекать и удерживать внимание читателя или слушателя и производить на него сильное впечатление за счет новизны форм, их своеобразия и необычности [Хазагеров, 1996: 4]. Образная речь, отличная от нейтрального языкового стандарта, становится семантически более емкой и доставляет подлинное эстетическое наслаждение. Именно экспрессия такой речи, пишет Н.Е. Малова, делает любой текст «эстетически обусловленным и позволяет автору наиболее ясно выразить свое мировидение, расставить акценты на наиболее важных эпизодах» [Малова, 2011].

Экспрессивная функция выразительных средств рассматривается нами как ведущая. Она свидетельствует о наличии в языковой единице определенной совокупности семантико-стилистических признаков, которые указывают на стремление автора текста выразить собственное отношение к предмету речи, что подразумевает и нарушение стандартных представлений о реальной действительности. Языковой инструментарий выразительности поистине безграничен: он предусматривает и нарушение языковых норм, и особый выбор языковых средств различных уровней, которые способствуют наиболее полному воплощению замысла автора и одновременно его точному пониманию адресатом.

В качестве основных средств выразительности речи традиционно рассматриваются тропы и фигуры. Выделение этих «цветов красноречия» известно еще со времен античности. Современный подход к выразительным средствам связан с выявлением закономерностей и механизмов их функционирования в речи (Э.М. Береговская, Г.Г. Хазагеров, Ж. Женетт, А. Тринон, А. Горнфельд и др.), изучением их текстообразующих возможностей (О.Г. Ревзина, Л.Ф. Тарасов, Н.А. Сырма и др.), исследованиями в структурно-системном плане (А.П. Сковородников, В.П. Москвин и др.), рассмотрением с позиций прагмалингвистики (Н.Ф. Алефиренко) и т.п.

Средства выразительности, обладая семантической насыщенностью и синтагматической неоднозначностью, широко используются в различных текстах - художественных, деловых, публицистических, политических, судебных, разговорных и др. Отметим, что при их изучении исследователи нередко противопоставляют две контрастные формы выражения - художественную и 
нехудожественную речь, подчеркивая преобладающее функционирование выразительных средств в художественных произведениях. Вместе с тем велика их роль и в нехудожественных текстах, благодаря чему такие тексты качественно изменяются, приобретая художественную образность, стилистически обогащенный язык, становясь более воздейственными, интерактивными.

Так, рассматривая отличительные особенности выразительности нехудожественного текста, Е.С. Чигирева выделяет два основных типа данной характеристики речи - логико-семантический, который выражается в тематическом воздействии на реципиента и отражает умение автора четко и последовательно выражать свои мысли, и художественно-образный, оказывающий эстетическое воздействие [Чигирева, 2016: 375].

Исследователи подчеркивают особую важность изобразительно-выразительных средств в деловой коммуникации, которая в настоящее время приобретает все более международный характер и осуществляется с использованием иностранного языка. Так, М.Л. Дьякова пишет, что при использовании делового английского языка не следует забывать о стилистических и прагматических возможностях языка, поскольку включение в речь стилистических средств и приемов обогащает и оживляет деловое общение, создавая в итоге благотворный бизнес-климат и обеспечивая высокую результативность деловых отношений [Дьякова, 2015: 116].

С быстрой эволюцией современного бизнеса или предпринимательской деятельности, нацеленной на получение дохода, наблюдаются изменения в деловой коммуникации и возникает необходимость выделения особого фрагмента языковой картины мира «Бизнес». Подчеркивая сложность и многокомпонентность этого фрагмента у представителей английской лингвокультуры, исследователи объясняют это чрезвычайно важной ролью, которую играет профессиональная самореализация в жизни представителей англоязычного общества, а наиболее значимой сферой такой реализации признается бизнес.

Как следствие, в типологии деловых текстов выделяется отдельный вид текста - бизнес-текст (бизнесдискурс). В отличие от официально-делового текста он стремится к разнообразию и не ограничивается использованием языковых штампов, характерных для типичных ситуаций деловой коммуникации; денотативный компонент его лексических единиц активно обогащается многочисленными коннотативными элементами; он избегает строгой регулятивно-императивной направленности, документальности, конвенциональности, увеличивая таким способом результативность конкретного коммуникативного акта; наполняется экспрессивностью и, следовательно, выразительностью. Л.М. Гальчук характеризует тематическую группу «Бизнес» в английском языке как макрополе с большим количеством неологизмов, как лексико-семантических, так и фразеологических, у которых коннотативные составляющие и прагматические характеристики ярче всего раскрываются «в публицистической разновидности английского делового дискурса с ее ярко выраженными целеполаганием и ориентацией на результат» [Гальчук, 2016: 86-87].

В современной лингвистической науке англоязычная деловая коммуникация, пишет А.В. Потапова, относится к наиболее популярным направлениям исследования. Рассматриваемые с конца XX века в рамках дискурсивной теории бизнес-тексты изучаются в совокупности с экстралингвистическими факторами как компоненты, участвующие во взаимодействии людей и механизмов их сознания [Потапова, 2017: 100]. В основу образно окрашенной деловой лексики заложен антропоцентричный вектор, обусловленный стремлением человека отразить окружающую действительность со своих позиций.

В данной статье акцентируется внимание на языковой выразительности делового текста и необходимости обучения этому аспекту в ходе преподавания иностранного языка, и в качестве примера успешной реализации такого подхода мы обращаемся к учебному пособию по английскому языку "Franchising" М.Е. Пономаревой, предназначенного для студентов 1 курса магистратуры международно-правового факультета Всероссийской академии внешней торговли [Пономарева, 2015]. Данный выбор обусловлен тем, что в указанной работе автор нацелен не только на развитие у обучающихся правильной иноязычной деловой речи с точки зрения формы и содержания применительно к теме "Franchising", но и на формирование более свободной, образной, стилистически и жанрово разнообразной речи на английском языке, что, безусловно, является важнейшей задачей в подготовке будущих профессионалов в области внешнеэкономической деятельности.

В учебном пособии М.Е. Пономаревой содержится широкий выбор текстов, посвященных франчайзингу. Среди них - тексты, обладающие строгим официально-деловым стилем (например, договор франчайзинга "franchise agreement"), для которых характерны стандартные языковые шаблоны и фразы, ограниченное употребление средств выразительности, нейтральная тональность; учебно-академические деловые и бизнестексты тексты, ориентированные на формирование англоязычной лексико-грамматической, терминологической и тематической компетентности обучаемых (напр., "Going it alone", "Buying into a franchise: pros \& cons"), коммуникативно-направленные, нацеленные на развитие исследовательских, аналитических, риторических, предпринимательских и иных качеств будущих профессоналов в области внешнеэкономической деятельности; деловые медиатексты, относящиеся к публицистическому стилю, эмотивно заряженные для более эффективного 
воздействия на аудиторию, включающие и тропеические средства, и стилистические фигуры (статьи "Franchises provided big boost to nation's economy", "Several types of part-time franchises" и др.).

С точки зрения формирования стилистически разнообразной, образной речи при обучении деловому и профессиональному английскому языку, наибольший интерес представляют прежде всего специализированные публицистические деловые тексты. Их отличительными особенностями выступают актуальность и оценочность; большая роль в них отводится визуализации представленной информации и интерактивной связи с читателями и слушателями. Стремление журналиста доказать правильность своей позиции придает публицистическому стилю такие качества, как полемичность, эмоциональность, и в выражении такого стремления велика роль выразительных средств.

В научных трудах таких авторов, как А.А. Дергунова, Т.М. Грушевская, О.В. Шашкова, Е.А. Шоболова, Л.А. Тараканова, А.И. Анохин и др., отмечается, что экспрессия газетной речи может осуществляться в различных формах: в побудительном характере речи, использовании качественно-оценочных частей речи, отборе фразеологии, характере метафоризации; для наибольшего воздействия на читателя публицистика располагает богатым арсеналом синтаксических средств, включая риторические фигуры, анафору, эпифору, антитезу, параллелизм предложений и другие стилистические фигуры; на графическом уровне образность передается с помощью графических и орфографических выделений и т.п.

Рассмотрим особенности использования средств выразительности в аспекте обучения профессиональной англоязычной речи по теме «Франчайзинг» и в качестве основного источника примеров обратимся к деловым англоязычным текстам из учебного пособия М.Е. Пономаревой "Franchising".

Анализ текстов свидетельствует о неоднократном использовании авторами идиом, которые, по словам А.И. Смирницкого, представляют собой устойчивые выражения, «основанные на метафоре, ясно осознающейся говорящими» [Смирницкий, 1998]. На современном этапе развития отечественного и зарубежного языкознания изучение идиом продолжает оставаться актуальным направлением, особенно применительно к речевой деятельности и такой ее разновидности, как устный англоязычный бизнес-дискурс и медийный бизнес-дискурс, в которых такие речевые единицы встречаются чаще всего [Вершинина, 2012: 713].

В следующем предложении "This royalty structure means that the franchisee pays more as the business turnover increases, but by the same token the franchisor has a direct financial interest in helping its franchisees increase their turnover" встречается идиома by the same token, которую автор пособия графически выделяет и предлагает перевод - «что является лишним тому доказательством», учитывая сложности перевода идиоматических сочетаний. Примером другого использования идиоматики в деловом медиатексте учебного пособия является выражение to make to live off of - «чтобы кататься как сыр в масле», создающее убедительный образ материального благополучия для лиц, вступающих в такую форму отношений как франчайзинг. Значительный прагматический эффект в предложении "Rail franchising has hit the buffers" достигается с помощью идиомы hit the buffers («заходить в тупик»), создающей более яркий образ неудачи в бизнесе по сравнению с нейтральными to stop или to fail.

Особую выразительность текстам, посвященным франчайзингу, придают устойчивые выражения, в большей степени характерные для спортивной сферы, семантически наполняющие деловую коммуникацию духом соперничества, стремлением к победе и высоким результатам, например: "And people who are looking to join us, looking for seasonal business is a big draw" («быть в выигрыше»).

Безусловно, важна и роль метафоры в деловых текстах, выступающей и как эффективное средство воздействия в деловой коммуникации благодаря своей необычности и образности. Природа метафоризации позволяет адресату не только получить целостное представление о соответствующем референте, но и указывает на его характерные признаки и свойства, перенесенные с исходного объекта. Например, в предложении "We serve coffee, we have fun, we get to wear outfits like these to work every day, you may have seen our wavers" в роли метафоры выступает слово wavers, которое, с учетом контекста, переводится как «ряженые зазывалы», обозначая лиц, одетых в костюмы с рекламой и предлагающих для продажи различные товары. Создаваемый метафорой яркий образ, основанный на ассоциации с такими народными персонажами, как скоморохи, коробейники, зазывалы и т.п., придает выражению и описываемому процессу характер праздника и веселья. В данном предложении отметим также комбинацию лексико-семантических и синтаксических выразительных средств английского языка за счет включения в конструкцию параллелизма ("we serve coffee, we have fun, we get to wear outfits"), усиливающую прагматическое воздействие на реципиента делового текста.

В предложении “The part-time franchise option has spread the diverse wings of the franchising industry today" автором с помощью метафоризации выражения to spread the wings («расправить крылья») создается яркий образ современного процесса становления «на крыло» франчайзинга с неполной занятостью. 
В следующем примере "With flexible working hours and a fantastic reward for sevices offered, such part-time franchise options have rocketed to the peak of popularity in no time" семантический перенос по сходству с движением ракеты позволяет по-новому, а следовательно, действеннее описать стремительный взлет популярности новых тенденций в области франчайзинга. Значительный прагматический потенциал ощущается и в предложении "For me, franchising is all about taking considered risks and having the entrepreneurial hunger to grow", достигаемый с помощью метафоры the entrepreneurial hunger, создающей яркий образ желания поддерживать чувство голода для стимулирования развития предпринимательской деятельности в сфере франчайзинга.

Анализ предложения "So, our tag line is our bottom line" позволяет сделать вывод о довольно широком арсенале выразительных средств, применяемых в англоязычном деловом тексте и включающих также фонетические риторические средства и приемы. Использование рифмы tag line («слоган») и bottom line («прибыль») способствует за счет созвучия лучшему восприятию фразы, а ее краткость и «рубленность» позволяет сохранить в памяти адресата основную идею, содержащуюся в информации о франчайзинге. Обратим внимание, что в деловой коммуникации звуковая выразительность имеет иное целеполагание, чем в художественной речи - она направлена на убеждение адресата в своей правоте в отличие от нацеленности на сопереживание в художественном тексте.

Отметим, что помимо указанных выше средств выразительности, в деловые тексты учебного пособия вош- ли многочисленные эмоциональные и оценочные прилагательные и наречия, также участвующие в создании эффекта словесной формой привлекать и удерживать внимание адресата и производить на него яркое впечатление, например, ideal part-time franchise opportunities, extremely rewarding part-time franchise opportunities, unique opulent menus и др.

В заключении подчеркнем, что при обучении деловому английскому языку преподаватели нередко основное внимание обращают на лексико-грамматическую, терминологическую и тематическую стороны учебного процесса, не уделяя должного внимания обучению различным приемам и средствам выразительности, присущим оригинальному английскому деловому тексту, особенно бизнес-тексту и медийному деловому тексту. Включение в учебное пособие и процесс обучения деловой коммуникации на английском языке стилистически и жанрово разнообразных текстов, внимание к прагматическому потенциалу текста и его средствам воздействия на получателя информации позволяет сформировать специалиста, свободно владеющего общим и профессиональным английским языком и убедительно воздействующего на партнера по коммуникации. Отличным примером такого комплексного подхода служит учебное пособие М.Е. Пономаревой "Franchising" для студентов 1 курса магистратуры международно-правового факультета Всероссийской академии внешней торговли, нацеленное на развитие, совершенствование устной и письменной деловой и профессиональной англоязычной речи обучающихся в аспекте ее выразительности с учетом стилистического многообразия.

ЛИТЕРАТУРА

1. Вершинина М.И. Идиомы в отечественном и зарубежном языкознании // Известия Самарского научного центра РАН, 2012. - Т. 4. - № 2. - С. 710 -714

2. Гальчук Л.М. 0 бизнесе «по-новому»: к проблеме неономинаций в английском деловом дискурсе конца XX - начала XXI вв. // Идеи и идеалы, 2016. № 1 (27). - С. 85-95

3. Дьякова М.Л. Метафора в деловом английском как средство воздействия на целевую аудиторию // Внешнеторговое консультирование, 2015. - № 1. C. $116-120$

4. Малова Н.Е. Реализация эстетической функции в художественных текстах // Вестник Адыгейского государственного университета. Серия 2: Филология и искусствоведение, 2011. - № 3. - Режим доступа: https://cyberleninka.ru/article/n/realizatsiya-esteticheskoy-funktsii-v-hdozhestvennyh-tekstah (дата обращения: 18.06.2021)

5. Пономарева M.E. Franchising. Учебное пособие по английскому языку для студентов 1 курса магистратуры МПФ. - М.: ВАВТ Минэкономразвития России, 2015. -65 C.

6. Потапова А.В. Англоязычный бизнес-дискурс как самостоятельный тип дискурса // Известия Волгоградского государственного педагогического университета. Серия: Филологические науки, 2017. - С. 98-100. - Режим доступа: https://cyberleninka.ru/article/n/angloyazychnyy-biznes-diskurs-kaksamostoyatelnyy-tip-diskursa (дата обращения: 24.06.2021)

7. Смирницкий А.И. Лексикология английского языка. - М.: МГУ, 1998. - 260 с.

8. Хазагеров Т.Г. Экспрессивный стиль как основная категория экспрессивной стилистики. // Проблемы экспрессивной стилистики. / Под. ред. Т.Г. Хазагерова. - Ростов-на-Дону: РГУ, 1996. - Вып. 3. - С. 3-10

9. Чигирева Е.С. Выразительность нехудожественной речи // Преподаватель XXI век, 2016. - № 3. - С. 371-375 